\title{
Eppur si muove...
}

\author{
Maria Helena Serôdio
}

Com estas palavras, proferidas - não sem risco pessoal, em 1633 - na sequência de ser obrigado pela Inquisição a abjurar da teoria heliocêntrica, Galileu, ilustre matemático, físico e filósofo italiano, exprimia o que cientificamente, e na correlativa exigência de honestidade intelectual e rigor ético, não poderia deixar de admitir: "e, todavia, a terra move-se"...

E assim parece ser verdade também para o teatro que se vai fazendo entre nós: apesar da denegação crescente de que tem sido alvo por parte de quem se esperaria maior apoio e estímulo (os poderes públicos), o teatro em Portugal "move-se" e, muitas vezes, comove-nos pelo modo como convoca o riso e a dor, o desespero e a melancolia, celebrando sempre a vida e a vivência em colectivo, e fazendo-o muitas vezes com eficácia expressiva e superior qualidade artística.

Por isso a Associação Portuguesa de Críticos de Teatro, uma vez mais, quis premiar o teatro feito, distinguindo alguns criadores - de entre os muitos - que em cena vão esconjurando mundos ficcionais e recortando-os em flagrante "delito artístico" à frente de um público.

0 Prémio foi este ano atribuído ao Festival de Teatro de Almada, por decisão unânime do seu júri, e as palavras expressivas de João Carneiro sobre a sua regularidade (desde 1984) e inequivoca qualidade tocam justamente neste ponto:

\footnotetext{
A regularidade do Festival - duas semanas em Julho - instalou-se como uma das suas marcas. Num mundo, num pais e num contexto em que a noção de certeza é um absurdo, e a criação de expectativas apenas serve para tornar as pessoas familiares com a ideia de catástrofe ou, pelo menos, infelicidade, tal atitude de fidelidade é um milagre.
}

E é com a declaração dos vários membros do júri, relativamente ao Prémio e às Menções Especiais - neste caso entregues aos responsáveis criativos dos espectáculos Ah, os dias felizes (pelo Teatro Nacional São João), Os meus sentimentos (por Mónica Calle e Culturgest) e Rei Lear (pelo Teatro Oficina) - que preparámos o "Dossiê temático" deste número, como por norma ocorre nas edições da revista em Junho. Neste ano, porém, publicamos também a intervenção/manifesto que o actual Director da Companhia de Teatro de Almada (e do Festival Internacional do Teatro de Almada) - Rodrigo Francisco - proferiu na cerimónia de atribuição do Prémio.

0 que foi também diferente na festa da entrega do Prémio deste ano - depois de vários anos a realizá-la em Lisboa - foi ter decorrido no Porto, no belo Mosteiro de São Bento da Vitória, por amabilidade do Director do
Teatro Nacional São João - Nuno Carinhas -, e com a preciosa colaboração da excepcional equipa técnica e de todos quantos devotadamente trabalham naquele Teatro. E isso traduziu-se numa festa muito bonita que - por generosidade do fotógrafo João Tuna - podemos evocar aqui em breve registo fotográfico.

A fotografia é, aliás, a matéria artística que vem animando o projecto OPSIS, dirigido por Maria João Brilhante no Centro de Estudos de Teatro (CET) - e já online no seu sítio electrónico http://opsis.fl.ul.pt/ - e que nos oferece, no "Portefólio" deste número, uma preciosa colecção de imagens que serviu uma exposição na Faculdade de Letras da Universidade de Lisboa. Acompanhando o colóquio "0 feminino no teatro", que decorreu em Março deste ano, esta exposição revelava modalidades do retrato de actrizes - o retrato oficial, o retrato à civil, o retrato em representação ou em personagem, o retrato alegórico, entre outras tipologias - e vem aqui, em texto breve, comentada pela própria directora do projecto, que esclarece bem como a fotografia mostra, ilumina, "encena" ou inventa.

Fotografias, mas também imagens de cartazes, desenhos e gravuras, compõem o material iconográfico de que se serviu Paula Magalhães para - na secção "Arquivo solto" - recordar um dos grandes êxitos dos teatros de feira: 0 processo do rasga. Analisando as razões maiores da fama, que este espectáculo então obteve, o artigo confere um colorido interessante a esta forma de representação popular e integra-o no "sistema" dos teatros do último quartel do séc. XIX, destacando o protagonismo, neste campo, dos Irmãos Dallot. A capacidade de evocar o ambiente em que decorriam as representações, as modas artísticas que traziam à cena músicas conhecidas em versões paródicas, a sua grande eficácia teatral, a recepção na imprensa, tudo nos é dado em escrita apelativa e com base em cuidada investigação pelas muitas páginas de periódicos que a autora compulsou.

Alguns outros artigos - e mesmo secções - deste número invocam cruzamentos internacionais como formato e substância que vamos reconhecendo no teatro e nas aprendizagens de escrita e criação também entre nós. Exemplo maior é, sem dúvida, a longa entrevista, que integra a secção "Na primeira Pessoa", e na qual Rui Pina Coelho e Joana d' Eça Leal procuram perceber o trajecto e formas de pensar o teatro por parte de Tiago Rodrigues, fundador (com Magda Bizarro) do Mundo Perfeito. 0 seu discurso, conhecedor do teatro de hoje e dialogando com essa realidade de forma bastante directa, assenta numa ideia de criatividade nómada. Todavia, isso não exclui a 
possibilidade - e a expressa vontade - de integrar nos seus espectáculos matérias, lugares e palavras nossas, quer numa hipotética viagem até ao jardim zoológico (Tristeza e alegria na vida das girafas, 2011), quer ainda na recordação dos rigores censórios do antes do 25 de Abril (Três dedos abaixo do joelho, 2012).

Na secção "Estudos aplicados", José Gabriel López Antuñano desenha uma importante geografia de novas formas estéticas na Europa nossa contemporânea, e Anabela Mendes recorda os sentidos e consequências da escrita de Heiner Müller ao reconfigurar o mundo d' As relações perigosas de Pierre Laclos na sua obra Quarteto. Cruzamento internacional e artístico é ainda a matéria de um workshop - com André Lepecki e Vera Mantero - de que Paula Caspão nos dá uma cuidada evocação. Ainda nesses cruzamentos internacionais cabe a referência a um site italiano para o qual Ana Campos nos chama a atenção e que preenche aqui a seç̧ão "Em rede".

Um dos aspectos, que vem marcando o campo actual do teatro entre nós, é o interesse e o valor de uma nova dramaturgia que parece atrair cada vez mais jovens, e o facto de esses textos estarem já a ser "exercitados" em cena, até pela relação privilegiada que estes projectos têm com companhias e editoras. É o caso do Projecto Cassandra de que nos fala Jorge Palinhos ainda nesta secção de "Estudos aplicados" e que foi lançado em Coimbra, tendo já produzido várias formulações dramáticas - de Cláudia Lucas Chéu, Jorge Louraço Figueira, Marta Freitas, Mickae de Oliveira, Jorge Palinhos - e que foi ganhando corpo cénico sob a orientação de Nuno M. Cardoso.

Também na secção "Leituras" nos chegam trabalhos de reflexão em torno de novos textos portugueses em colecções várias e que já tiveram, aliás, a sua estreia em palco: Ricardo Neves-Neves viu publicada a sua peça $A$ porta fechou-se e a casa era pequena, pela Companhia das Ilhas; Já passaram quantos anos, perguntou ele..., de Rui Pina Coelho, foi publicada (com alguns outros textos mais curtos) pelo Teatro Experimental do Porto; Tiago Rodrigues viu editadas três peças suas num só volume Três dedos abaixo do joelho, Tristeza e alegria na vida das girafas, Coro dos amantes - pela Imprensa da Universidade de Coimbra; e Jorge Gomes Ribeiro teve a sua peça interpelativa de $\dot{A}$ espeera de Godot editada pela Escola Superior de Teatro e Cinema: Em baixo e em cima: $A$ propósito de Beckett.

Merecem ainda destaque nesta secção "Leituras" a recensão de Rita Martins ao estudo de José Sasportes sobre A quinta musa, bem como a anual, sólida, e cada vez mais imprescindivel lista de "Publicações de teatro" em Portugal que, paciente e diligentemente, Sebastiana Fadda vai compondo em cada ano.

Entre as "Notícias de fora" vem um olhar atento e crítico de Constança Carvalho Homem sobre uma iniciativa à volta do novo circo em Edimburgo, e, por parte de Alexandra Moreira da Silva - com a competência que se Ihe reconhece -, uma reflexão em torno do Festival de Avignon, lembrando aspectos do seu passado e adiantando o que o novo Director, Olivier Py, se propõe fazer este ano.

Nos "Passos em volta" são evocados, em registo crítico de Eunice Tudela de Azevedo, alguns dos espectáculos integrados na primeira edição de um novo festival de teatro - o FITA: Festival Internacional de Teatro do Alentejo, realizado em Beja -, enquanto da capital do Alto Alentejo nos chega a análise de Christine Zurbach sobre Autos de Revolução, reencenados por Pierre-Étienne Heymann. Sebastiana Fadda elabora criticamente uma reflexão cuidada em torno do espectáculo dos Primeiros Sintomas sobre 0 retrato de Dorian Gray, de Oscar Wilde, cabendo ainda nesta secção a apreciação crítica, pela escrita de Ana Campos, de um espectáculo de cabaret alemão que Luísa Costa Gomes escreveu e que chegou até nós no Teatro do Bairro pela direcção de António Pires. A finalizar este percurso por alguns dos palcos portugueses, Vera Santos evoca Ocidente, um espectáculo que Victor Hugo Pontes encenou/coreografou a partir do texto de Remi De Vos, e Elisabeth Costa fala-nos da recente edição do Festival Anual de Teatro Académico de Lisboa - FATAL - que a Universidade de Lisboa vem organizando e que cumpriu agora a sua $15^{a}$ edição.

E é bom saber que a nova Universidade de Lisboa que resultou da fusão da Universidade "Clássica" de Lisboa e da Universidade "Técnica" de Lisboa - não abdicou deste projecto, até por acreditar na capacidade de ele se renovar, bem como de apurar a sua exigência artística, e por reconhecer que é já firme a tradição que "tem sabido" defender. E dando continuidade a uma política de reconhecimento cultural e artístico a celebrar em cada ano, o FATAL, por justificada razão e mérito incontestado, homenageou Emilio Rui Vilar.

Um agradecimento final é ainda devido a todos os que se envolveram na composição deste número da revista pela escrita, pelas fotografias, pelas aturadas leituras e múltiplas revisões, e por tantos outros gestos e actos de efectiva colaboração - bem como aos Teatros Nacionais (São João e D. Maria II) que, uma vez mais, se associaram generosamente à edição deste número através da publicitação das suas iniciativas. Sem esta extraordinária conflagração de cumplicidades e apoios, esta revista não existiria... 